\title{
A Small Compound KJ-28d Enhances the Sensitivity of Non-Small Cell Lung Cancer to Radio- and Chemotherapy
}

\author{
Hwani Ryu ${ }^{1,2}$, Hyo Jeong Kim ${ }^{1}$, Jie-Young Song ${ }^{1}{ }^{(0)}$, Sang-Gu Hwang ${ }^{1}$, Jae-Sung Kim ${ }^{1}$, \\ Joon Kim ${ }^{2}$, Thi Hong Nhung Bui ${ }^{3}$, Hyun-Kyung Choi ${ }^{3, *}$ and Jiyeon Ahn ${ }^{1, *(D)}$ \\ 1 Division of Radiation Biomedical Research, Korea Institute of Radiological \& Medical Sciences (KIRAMS), \\ Seoul 01812, Korea; hwanya85@kirams.re.kr (H.R.); hjkim@kirams.re.kr (H.J.K.); immu@kirams.re.kr (J.-Y.S.); \\ sgh63@kirams.re.kr (S.-G.H.); jaesung@kirams.re.kr (J.-S.K.) \\ 2 Department of Biology, Korea University, Seoul 02841, Korea; joonkim@korea.ac.kr \\ 3 Department of Medicinal Chemistry, Jungwon University, Goesan 28024, Korea; \\ buihongnhung103@gmail.com \\ * $\quad$ Correspondence: hkchoi45@jwu.ac.kr (H.-K.C.); ahnjy@kirams.re.kr (J.A.); Tel.: +82-2-970-1311 (J.A.)
}

Received: 10 October 2019; Accepted: 29 November 2019; Published: 29 November 2019

check for updates

\begin{abstract}
We previously reported on a poly (ADP-ribose) polymerase (PARP) 1/2 inhibitor $\mathrm{N}$-(3-(hydroxycarbamoyl)phenyl)carboxamide (designated KJ-28d), which increased the death of human ovarian cancer BRCA1-deficient SNU-251 cells. In the present study, we further investigated the antitumor activities of KJ-28d in BRCA-proficient non-small cell lung cancer (NSCLC) cells to expand the use of PARP inhibitors. KJ-28d significantly inhibited the growth of NSCLC cells in vitro and in vivo, and induced DNA damage and reactive oxygen species in A549 and H1299 cells. Combined treatment with $\mathrm{KJ}-28 \mathrm{~d}$ and ionizing radiation led to increased DNA damage responses in A549 and H1299 cells compared to KJ-28d or ionizing radiation alone, resulting in apoptotic cell death. Moreover, the combination of KJ-28d plus a DNA-damaging therapeutic agent (carboplatin, cisplatin, paclitaxel, or doxorubicin) synergistically inhibited cell proliferation, compared to either drug alone. Taken together, the findings demonstrate the potential of $\mathrm{KJ}-28 \mathrm{~d}$ as an effective anti-cancer therapeutic agent for $B R C A$-deficient and -proficient cancer cells. KJ-28d might have potential as an adjuvant when used in combination with radiotherapy or DNA-damaging agents, pending further investigations.
\end{abstract}

Keywords: poly (ADP-ribose) polymerase inhibitor; non-small cell lung cancer; DNA damage; radiotherapy; chemotherapy; combination therapy

\section{Introduction}

Lung cancer is one of the most commonly occurring cancers worldwide. Non-small cell lung cancer (NSCLC) accounts for more than $84 \%$ of all lung cancers [1]. Despite recent advances in our understanding of the molecular and genetic basis of lung cancer and improvements in therapy, the 5-year survival rate of patients with NSCLC in both Korea (23.7\%) and the United States (23\%) is lower than that for many other leading cancers [1,2]. The standard chemotherapy treatment used for NSCLC is either the platinum-based (cisplatin, carboplatin, etc.) or taxane-based (paclitaxel, docetaxel, etc.) regimens, or epidermal growth factor receptor (EGFR) inhibitors. However, because of the lack of response or resistance to those therapies, many patients with NSCLC consider new alternative therapies or receive combination therapies [3]. Therefore, the development of novel drugs or strategies of combination therapy with existing drugs is urgently required. 
Ionizing radiation (IR) is directly cytotoxic through the induction of DNA single- or double-strand breaks (DSB) and indirectly cytotoxic through the generation of reactive oxygen species (ROS), leading to tumor cell death and thus cancer treatment. Similarly, platinum- or taxane-based chemotherapeutic agents inhibit cell mitosis through the induction of DNA damage. DNA lesions induced by IR or cytotoxic agents can be repaired by six major DNA repair pathways: base excision repair, nucleotide excision repair, direct repair (i.e., $\mathrm{O}^{6}$-alkylguanine DNA alkyltransferase directly repairs DNA damaged lesions by removing $\mathrm{O}^{6}$-methylguanine), mismatch repair, homologous recombination (HR), and non-homologous end-joining pathways. NSCLC is characterized by genomic instability with mutations and translocations in oncogenes, such as the Ki-ras2 Kirsten rat sarcoma viral oncogene homolog proto-oncogene (KRAS), EGFR, ALK receptor tyrosine kinase (ALK), ataxia-telangiectasia mutated (ATM) or phosphatidylinositol-4,5-bisphosphate 3-kinase catalytic subunit alpha (PIK3CA), and tumor suppressor genes, such as the tumor protein $p 53$ (TP53), liver kinase B1 (LKB1), or Kelch-like ECH-associated protein 1 (KEAP1) [4-11].

Poly (ADP-ribose) polymerases (PARPs) are a family of 18 protein members that function as catalytic enzymes by adding ADP-ribose polymers to lysine residues of themselves and target proteins, a process termed poly (ADP-ribosyl)ation (PARylation). Among the proteins of the PARP family, PARP-1 and -2 are abundant nuclear enzymes involved in DNA damage repair, which involves binding to DNA breaks and facilitating the localization of repair enzymes, such as breast cancer 1/2 (BRCA1/2), to the sites of DNA damage $[12,13]$. Olaparib, rucaparib, niraparib, and talazoparib targeting PARP1/2 have been approved by the United States Food and Drug Administration (FDA) for the treatment of breast or ovarian cancer in patients harboring HR mutations that induce synthetic lethality in the $B R C A 1$ or $B R C A 2$ gene.

Evidence is accumulating that PARP inhibitors (PARPi) have therapeutic efficacy in cancer cells with high genomic instability by inducing synthetic lethality of cells with deficient or insufficient DNA repair [14-16]. Briefly, in this scenario, IR, or radiotherapy or cytotoxic chemotherapeutic agents that induce severe DNA damage could lead to insufficient DNA repair in targeted tumor cells. Consecutively, cells that adopt the "BRCAness" state could be treated with PARP inhibitor (PARPi) [17-20].

We have previously identified a potential novel PARPi, termed $N$-(3-(hydroxycarbamoyl)phenyl) carboxamide (designated KJ-28d). KJ-28d inhibited PARP-1/2 activities and displayed significant antitumor activity in human ovarian cancer BRCA1-deficient (BRCA1 mutation at 5564G>A) SNU-251 cells [21]. In this study, we further investigated the antitumor activity of $\mathrm{KJ}-28 \mathrm{~d}$ in $B R C A$-proficient cell lines, as well as the combination of $\mathrm{KJ}-28 \mathrm{~d}$ and DNA damage-inducing radiotherapy or cytotoxic chemotherapeutics in human NSCLC cells.

\section{Results}

\subsection{KJ-28d Inhibits Growth of Human NSCLC Cells In Vitro and In Vivo}

Among the reported novel PARP-1 inhibitors, we examined KJ-28d, as shown in Figure 1A, based on the prior demonstrations of its significant inhibitory activity against PARP-1, as well as antitumor activity in BRCA-deficient ovarian cancer cells [21]. Specifically, we assessed whether KJ-28d can inhibit the growth of BRCA-proficient cancer cells. Human NSCLC cells were treated with KJ-28d and growth inhibition was determined using the 3-(4,5-dimethylthiazol-2-yl)-2,5- diphenyltetrazolium bromide (MTT) assay. KJ-28d significantly inhibited the growth of A549, H1299, H460, and H1650 human NSCLC cells with a determined $\mathrm{IC}_{50}$ value, as shown in Figure 1B, and induced the sub-G1 phase (apoptotic cell) in A549 and H1299 cells, as shown in Supplementary Figure S1. 
A

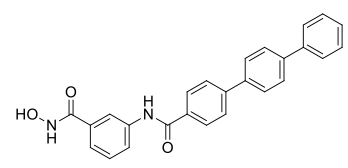

B

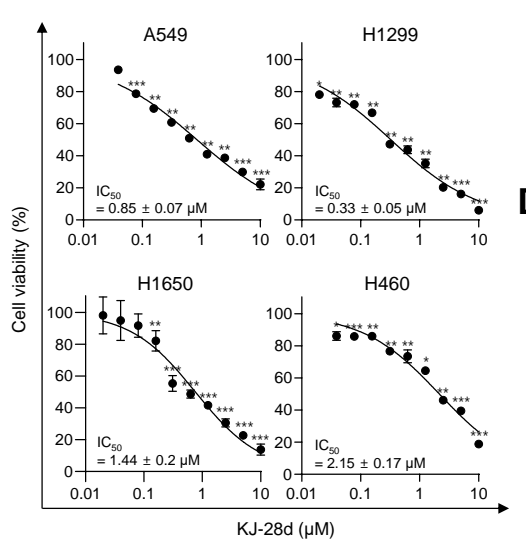

C

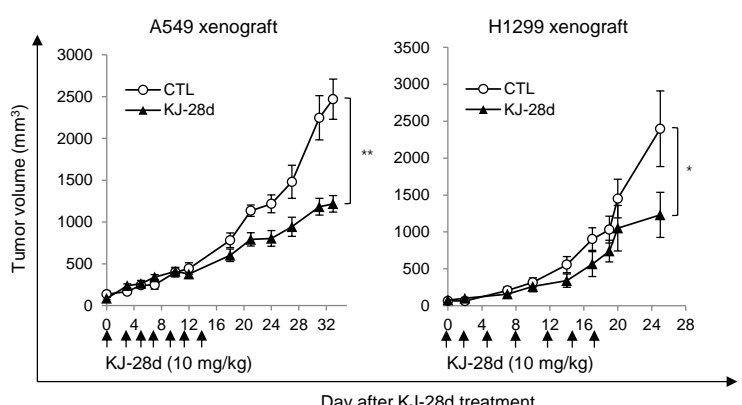

D

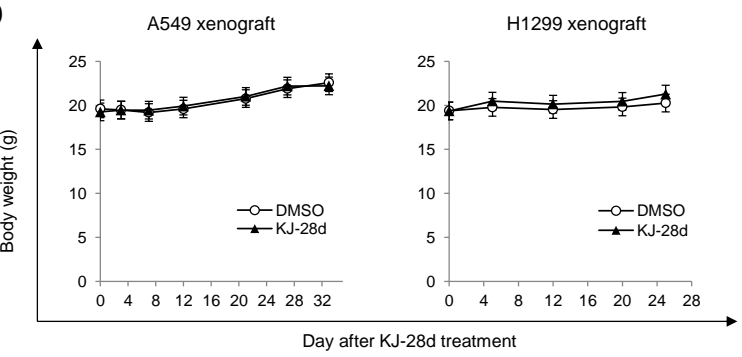

Figure 1. KJ-28d inhibits tumor growth of A549 and H1299 xenografts in nude mice. (A) The chemical structure of the KJ-28d compound. (B) A549, H1299, H1650, and H460 human non-small cell lung cancer (NSCLC) cells were treated with KJ-28d at the indicated concentrations for 5 days, and cell viabilities were determined by the MTT assay. Data are presented as means \pm standard deviation (SD) from at least three independent experiments. ${ }^{*} p<0.05,{ }^{* *} p<0.01,{ }^{* * *} p<0.001$ versus DMSO-treated control. (C,D) A549 cells and H1299 cells were subcutaneously injected into the thigh of the right hind leg of BALB/c nu/nu mice ( $n=3$ per group, A549; $n=4$ per group, H1299). Two weeks after tumor cell injection, $\mathrm{KJ}-28 \mathrm{~d}(10 \mathrm{mg} / \mathrm{kg}$ ) or DMSO (control) was intraperitoneally administered once every 2 or 3 days for seven times in total. (C) Longest $(\mathrm{L})$ and shortest $(\mathrm{W})$ tumor axes were measured, and tumor volume $\left(\mathrm{mm}^{3}\right)$ was calculated as $\mathrm{L} \times \mathrm{W}^{2} / 2$. Data shown represent average tumor volume $\left({ }^{*} p<0.05\right.$, $* * p<0.01$ ). Results are shown as means \pm SD. (D) The body weights of A549 and H1299 xenograft mice were determined once a week during the experiments. Data are shown as means \pm SD.

We next determined whether the antitumor effect associated with the in vitro $\mathrm{KJ}-28 \mathrm{~d}$ treatment could be translated into a similar effect in an in vivo xenograft mouse model. BALB/c-nu/nu mice were subcutaneously (s.c.) implanted with A549 or H1299 cells in the right hind leg, and when tumors were palpable (average diameter approximately $150 \mathrm{~mm}^{3} ; 10$ days post-implantation), mice were intraperitoneally (i.p.) administered a dose of $10 \mathrm{mg} / \mathrm{kg} \mathrm{KJ}-28 \mathrm{~d}$ or DMSO (control vehicle) once every 2 or 3 days for a total of seven times. KJ-28d treatment inhibited A549 or H1299 cell-derived tumor growth by $51 \%$ and $49 \%$, respectively, as compared with the respective vehicle, as shown in Figure $1 \mathrm{C}$. Additionally, to determine the toxicity of $\mathrm{KJ}-28 \mathrm{~d}$, we measured the body weight of mice. Mice treated with $\mathrm{KJ}-28 \mathrm{~d}$ did not show any difference in body weight as compared with control mice, as shown in Figure 1D. The results suggested that KJ-28d has antitumor activity for NSCLC cells in vitro and in vivo.

\subsection{KJ-28d Induces DNA Damage and Generation of ROS in NSCLC Cells}

Since PARPi induce accumulation of DNA damage [22,23], we sought to determine whether KJ-28d could induce DNA damage in NSCLC cells. The DNA damage was measured in A549 and H1299 cells at different time points after KJ-28d treatment by detecting the phosphorylation on Ser139 of the H2AX $(\gamma-\mathrm{H} 2 \mathrm{AX})$ histone protein, which is an indicator of the presence of DNA double-strand damage. KJ-28d induced $\gamma-\mathrm{H} 2 \mathrm{AX}$ in both cell types at the latest time point $(24 \mathrm{~h})$, as shown in Figure 2A. As treatment with $\mathrm{KJ}-28 \mathrm{~d}$ resulted in inducing a DNA damage response, we also investigated whether KJ-28d could augment ROS generation in NSCLC cells. Flow cytometry analysis showed that treatment of A549 
and H1299 cells with $5 \mu \mathrm{M} \mathrm{KJ-28d} \mathrm{led} \mathrm{to} \mathrm{distinctly} \mathrm{increased} \mathrm{ROS} \mathrm{levels,} \mathrm{which} \mathrm{were} \mathrm{then} \mathrm{reduced}$ following treatment with $\mathrm{N}$-acetyl-L-cysteine (NAC), a general free radical scavenger, as shown in Figure 2B,C. These results suggested that KJ-28d is able to exhibit antitumor activities in NSCLC cells through the accumulation of DNA damage and the generation of ROS.

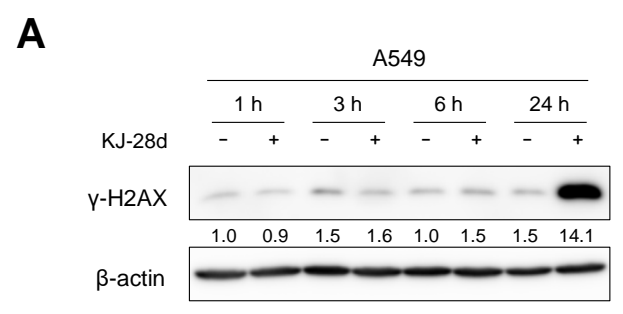

B

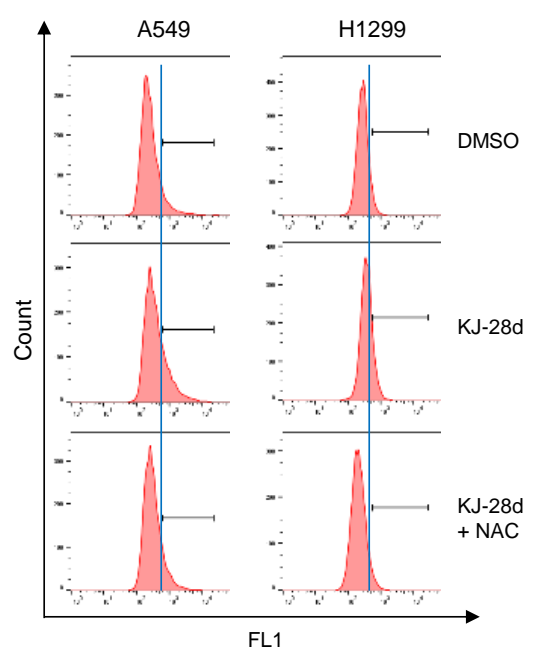

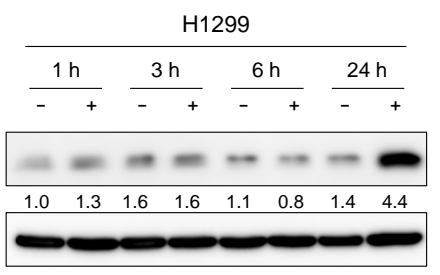

C

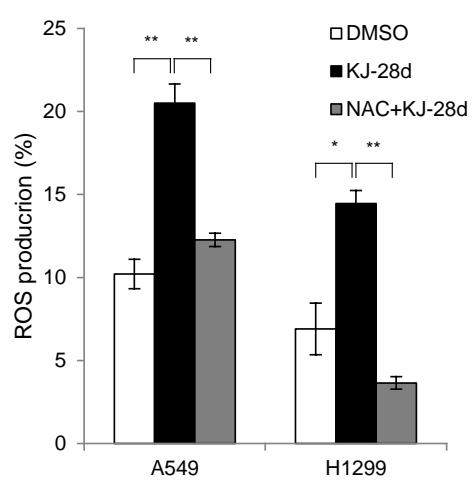

Figure 2. KJ-28d induces DNA damage and generation of reactive oxygen species (ROS). (A) A549 and H1299 cells were treated with $5 \mu \mathrm{M} \mathrm{KJ}-28 \mathrm{~d}$ at indicated time points and immunoblotted for the detection of expression of $\gamma$-H2AX. (B,C) A549 and H1299 cells were treated with 5 mM NAC for $1 \mathrm{~h}$, followed by KJ-28d for $24 \mathrm{~h}$ after incubation with $2^{\prime}, 7^{\prime}$-dichlorodihydrofluorescein diacetate (CM- $\mathrm{H}_{2}$ DCFHDA) for $30 \mathrm{~min}$. Total cellular ROS production was measured using flow cytometry. Data are representative of three independent experiments (B). The bar graph shows the quantitative analysis of flow cytometer data $(\mathbf{C})$. Data are presented as the mean \pm SD of three independent experiments. ${ }^{*} p<0.05,{ }^{* *} p<0.01$ versus corresponding values.

\subsection{KJ-28d Potentiated Ionizing Radiation-Induced DNA Damage and Radiosensitized NSCLC Cells}

As IR induces severe DNA damage, which can lead to overloading DNA repair capacity, it has been reported that PARP inhibitors enhance IR-induced DNA damage $[14,17,20,22]$. To examine whether $\mathrm{KJ}-28 \mathrm{~d}$ could induce increased DNA damage in combination with IR, DNA damage was measured in A549 and H1299 cells treated with KJ-28d and IR by detecting the presence of $\gamma$-H2AX. Immunoblot analysis revealed a significant increase in the phosphorylation levels of $\mathrm{H} 2 \mathrm{AX}$ protein as compared with KJ-28d or IR alone. Similarly, we observed high levels of staining of $\gamma$-H2AX foci in A549 and H1299 cells treated with both KJ-28d and IR, as shown in Figure 3A-C. PARylation by PARP-1 catalytic activity is a post-translational modification involved in DNA damage repair. To determine whether KJ-28d suppresses cellular PARylation, H1299 cells were treated with the indicated concentrations of either KJ-28d or olaparib, and A549 cells were treated with $5 \mu \mathrm{M} \mathrm{KJ}-28 \mathrm{~d}$ with or without IR. We observed that $10 \mu \mathrm{M}$ KJ-28d and 5 and $10 \mu \mathrm{M}$ olaparib inhibited protein PARylation in H1299, as shown in Figure 3D, and $5 \mu \mathrm{M}$ of KJ-28d inhibited IR-induced PARylation in A549 cells, as shown in Figure 3E. 
A

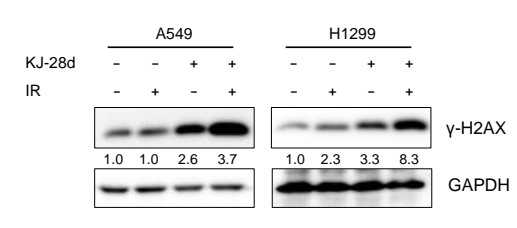

C

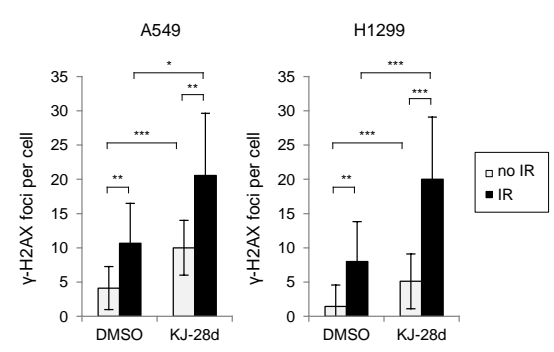

B

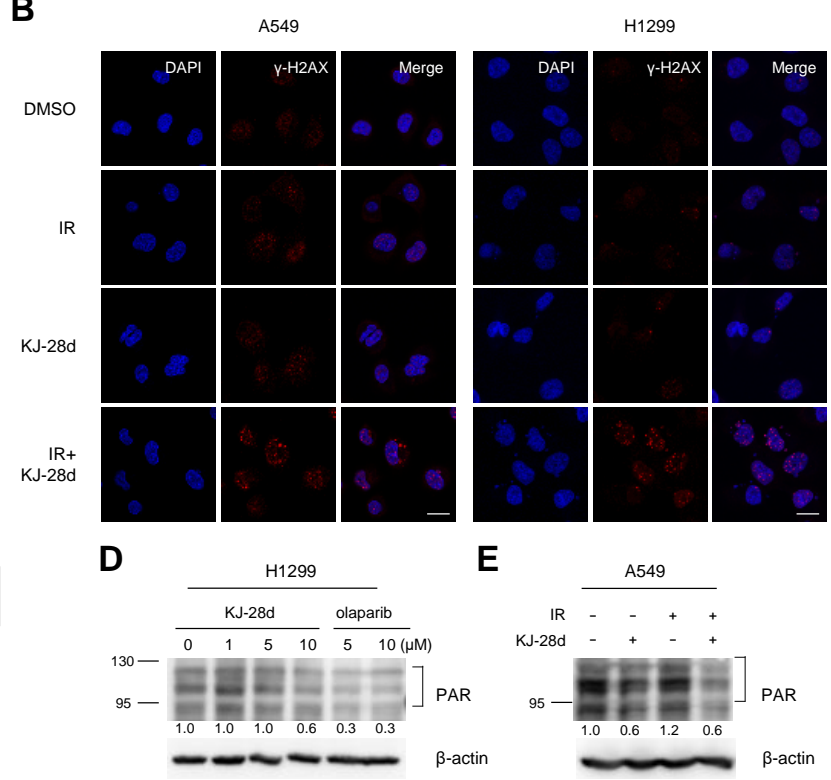

Figure 3. KJ-28d potentiates ionizing radiation (IR)-induced DNA damage responses. A549 and H1299 cells were treated with $5 \mu \mathrm{M} \mathrm{KJ}-28 \mathrm{~d} 2 \mathrm{~h}$ before IR (4 Gy) and incubated for $24 \mathrm{~h}$. The cell lysates were subjected to immunoblotting for detection of $\gamma-\mathrm{H} 2 \mathrm{AX}(\mathrm{A})$, whereas cells were immunostained for $\gamma-\mathrm{H} 2 \mathrm{AX}$ foci (red) and nuclei (DAPI: blue). Images were captured at $400 \times$ magnification. Scale bar: $20 \mu \mathrm{m}$ (B). Quantification of the number of $\gamma$-H2AX foci per cell (C). Data represent the mean \pm SD of three independent experiments. ${ }^{*} p<0.05,{ }^{* *} p<0.01$, ${ }^{* * *} p<0.001$ versus corresponding cells. (D) H1299 cells were treated with KJ-28d at indicated concentrations for $1 \mathrm{~h}$. (E) A549 cells were treated with $5 \mu \mathrm{M} \mathrm{KJ}-28 \mathrm{~d}$ and IR (4 Gy) and incubated for $1 \mathrm{~h}$. The cell lysates were immunoblotted for the detection of expression of PAR. $\beta$-actin was used as a loading control.

Since KJ-28d potentiated IR-induced DNA damage in NSCLC cells, we further examined whether KJ-28d inhibited IR-induced cell growth. A549 and H1299 cells were treated with KJ-28d $2 \mathrm{~h}$ before IR. The clonogenic survival assay revealed that $\mathrm{KJ}-28 \mathrm{~d}$ radiosensitized both cell lines, as shown in Figure 4A. Dose enhancement ratios (DER) of $0.75 \mu \mathrm{M} \mathrm{KJ}$-28d-treated (at a surviving fraction of 0.37) to DMSO-treated cells were 1.5 and 1.23 in A549 and H1299 cells, respectively. We next determined whether treatment with KJ-28d could induce apoptotic cell death in A549 and H1299 cells. Apoptotic cell populations of these cell lines were detected using flow cytometer analysis with annexin $\mathrm{V} /$ propidium iodide (PI) staining. Following treatment with $5 \mu \mathrm{M}$ of $\mathrm{KJ}-28 \mathrm{~d}$ and IR, the number of A549 and H1299 cells undergoing both early-stage (annexin V-positive/PI-negative) and late-stage (annexin V-positive/PI-positive) apoptosis increased significantly by 1.5 -fold compared to KJ-28d alone, respectively, as shown in Figure 4B. In addition, KJ-28d plus IR treatment increased the cleavage of caspase-3 in both cell lines, as shown in Figure 4C. Taken together, these results indicated that KJ-28d enhanced both IR-induced DNA damage and apoptotic cell death in A549 and H1299 human NSCLC cells. 
A

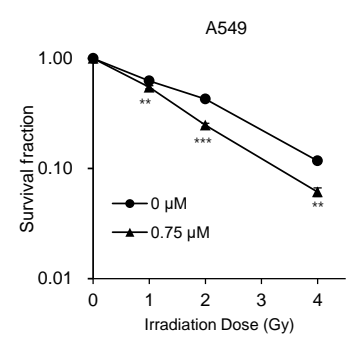

B

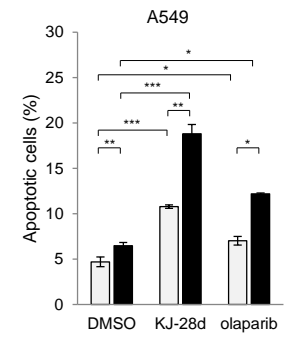

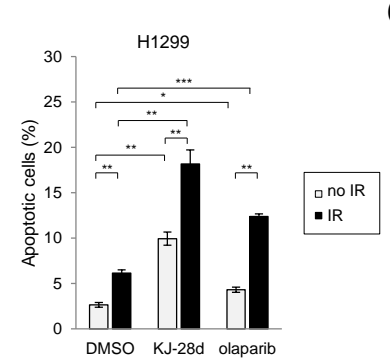

Figure 4. KJ-28d enhances the radiosensitivity of A549 and H1299 cells. (A) A549 and H1299 cells were treated with $0.75 \mu \mathrm{M} \mathrm{KJ}-28 \mathrm{~d}$ for $2 \mathrm{~h}$ before IR $(0,1,2$, and $4 \mathrm{~Gy})$. Clonogenic survival was measured 10 days after IR. Data are expressed as mean $\pm \mathrm{SD}(n=3)$ of the surviving fraction compared to non-irradiated cells. Colonies consisting of more than 50 cells were scored as survival colonies. (B) A549 and H1299 cells were treated with either $5 \mu \mathrm{M} \mathrm{KJ}-28 \mathrm{~d}$ or $5 \mu \mathrm{M}$ olaparib plus IR (4 Gy) for $48 \mathrm{~h}$. Apoptotic cells were determined using the APC-conjugated annexin V/PI staining. Cell populations were gated into four groups, as described in Section 4. Bar graphs represent the mean percentage of early (annexin V-positive/PI-negative) and late apoptotic cells (annexin V-positive/PI-positive). Data represent the mean $\pm \mathrm{SD}$ of three independent experiments. ${ }^{*} p<0.05,{ }^{* *} p<0.01,{ }^{* * *} p<0.001$ versus corresponding cells. (C) A549 and H1299 cells were treated with $5 \mu \mathrm{M} \mathrm{KJ}-28 \mathrm{~d}$ plus IR (4 Gy), and the cell lysates were subjected to immunoblotting for detection of cleaved caspase-3. $\beta$-actin was used as a loading control.

2.4. The Combination of KJ-28d and DNA Damage-Inducing Chemotherapeutic Agents Synergistically Inhibits NSCLC Cell Growth

In preclinical and clinical studies of advanced NSCLC treatment, administration of PARPi in combination with DNA-damaging therapeutic agents, such as platinum-based compounds, taxane-based compounds, and topoisomerase inhibitors, has demonstrated enhanced cytotoxicity [24-26]. As KJ-28d enhanced radiosensitivity of A549 and H1299 cells, we expected that $\mathrm{KJ}-28 \mathrm{~d}$ could increase cytotoxicity when combined with treatment with DNA DSB-inducing agents. A549 and H1299 cells were treated with KJ-28d and carboplatin, cisplatin, paclitaxel, or doxorubicin and evaluation of the synergistic effect of each pair-compound on cell viability was assessed using the MTT assay. Compared to treatment with $\mathrm{KJ}-28 \mathrm{~d}$ or each compound alone, combination treatments showed a strong synergistic effect in both A549 and H1299 cells, decreasing cell viability in a dose-dependent manner, as shown in Figure 5A,C. To interpret the effects of all drug combinations, cell viability observed with each concentration of a KJ-28d-compound pair was converted to a combination index (CI) score using the CompuSyn software by Chou-Talalay [27]. CI scores were categorized as synergistic ( $C I<0.9$, green), additive ( $1.1>C I \geq 0.9$, blue), or antagonistic $(\mathrm{CI}>1.1$, gray). We observed synergistic growth inhibition with a wide range of concentrations of KJ-28d and DSB-inducing agents in both cell lines, as shown in Figure 5B,D. Taken together, these results supported the conclusion that KJ-28d enhances the sensitivity of NSCLC cells to IR or chemotherapeutic agents of DNA-induced damage. 
A

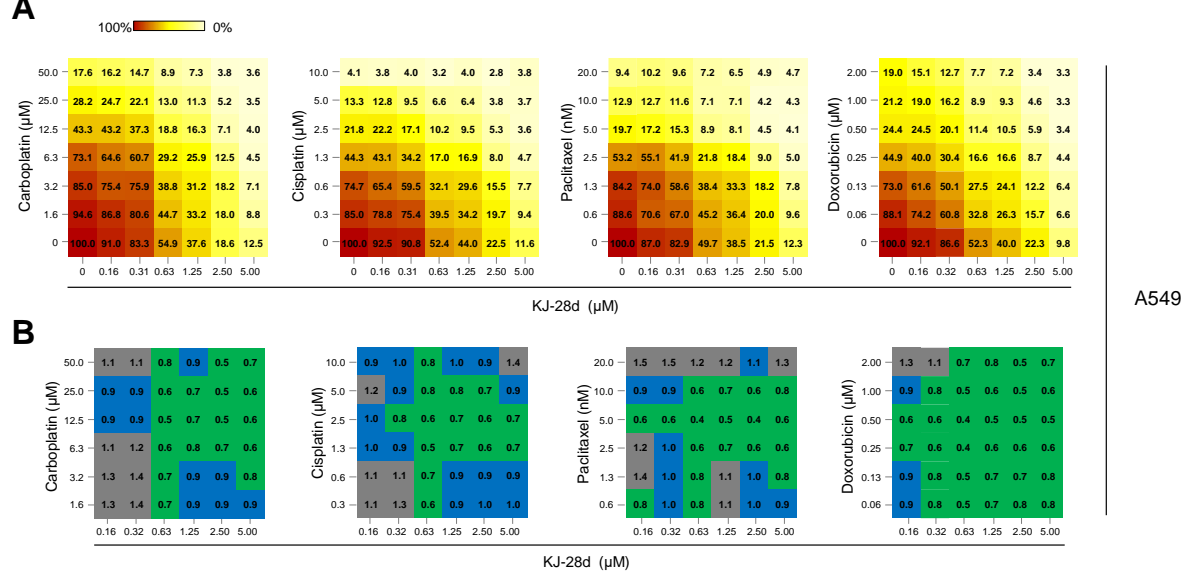

C

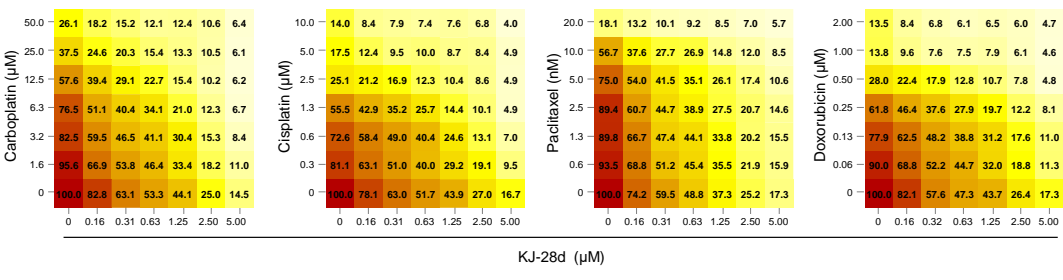

D

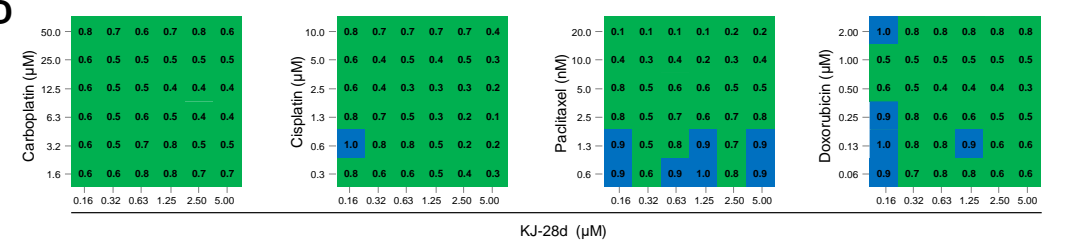

Figure 5. The combination of KJ-28d and DNA damage-inducing chemotherapeutic agents synergistically inhibits growth of A549 and H1299 cells. A549 (A) and H1299 (C) cells were treated with the single or combined administration of KJ-28d and carboplatin, cisplatin, paclitaxel, or doxorubicin at indicated concentrations. Cell viability was determined 5 days after the treatment by MTT assay. Relative viability (normalized to DMSO-treated cells) is shown for each combination at indicated concentrations. Data are from one representative experiment of three independently repeated experiments. (B,D) Summary of tables showing combination index (CI) scores of KJ-28d and each chemotherapeutic drug combined at indicated concentrations in A549 (B) and H1299 cells (D). CI scores were calculated using the CompuSyn software and categorized as synergistic $(\mathrm{CI}<0.9$, green), additive $(1.1>C I \geq 0.9$, blue), or antagonistic $(C I \geq 1.1$, gray). Each $C I$ score was one representative datum from treatment with the indicated concentrations of single- and paired compounds from more than three independent experiments.

\section{Discussion}

We previously identified KJ-28d as a novel PARP inhibitor that leads to increased cytotoxicity in human ovarian cancer BRCA-1-deficient SNU-251 (BRCA1 mutation at 5564G>A) cells, as well as in triple-negative human ovarian cancer $B R C A 1$ heterozygous (BRCA1+/-) MDA-MB-231 cells [21]. In this study, we further investigated the antitumor activity of KJ-28d on $B R C A$-proficient NSCLC cancer cells, as well as a combination approach with DNA damage-inducing agents to evaluate the synergistic therapeutic efficacy in human NSCLC cells.

NSCLC is a type of cancer with a high mortality rate. Most patients with NSCLC receive treatment with platinum-based drugs, such as cisplatin or carboplatin, as first-line standard therapy. However, many patients who initially benefit from such chemotherapies gradually acquire chemoresistance. Thus, the development of novel therapies and strategies, including combination therapies, is needed. KJ-28d can inhibit the growth of various cancer cells, including NSCLC, breast, and colorectal cancer cells, 
as shown in Supplementary Figure S2. We specifically focused on NSCLC and revealed its antitumor effects on A549 and H1299 cells both in vitro and in vivo. A549 cells have a KRAS oncogenic mutation with c-Myc amplification, while H1299 cells are TP53 mutant cells, as shown in Supplementary Table S1. Many studies have shown that KRAS-driven c-Myc amplification and TP53 correlate with genomic instability, thereby compromising DNA damage repair (DDR), causing the cells to be vulnerable to DDR inhibiting agents [28]. We observed that KJ-28d induced DNA damage and ROS generation in A549 and H1299 cells, which may facilitate cell death of NSCLC cells. The suppressed cellular PARylation might contribute to inducing DNA damage responses. Recent studies have suggested that PARPi can induce ROS generation due to DNA double stranded breaks. This is considered a characteristic of PARP inhibitors in DNA repair-deficient cells, as well as tumor suppressors or oncogene-mutated cells. Thus, PARPi may crosstalk with other signals [20,29]. In that regard, FDA-approved PARPi compounds have been studied to expand clinical use of PARPi in NSCLC [26,30,31].

Although the rationale for the use of PARPi was based on the reported induced synthetic lethality shown in BRCA-deficient cancer cells, preclinical and clinical studies suggested that PARPi could potentially be used as a combination partner with DNA-damaging agents in BRCA-proficient cancer cells $[26,32,33]$. Approximately $50 \%$ of patients with NSCLC receive radiotherapy during their treatment course [34]. Radiotherapy is an effective treatment modality, causing severe DNA damage. However, it can only treat tumors at defined doses because of the side effects to surrounding normal tissues. Although PARPi is not yet considered as a radiosensitizer in patients with ovarian cancer harboring BRCA1/2 mutations in the clinic, the combination of radiotherapy with PARPi could provide promising synergistic therapeutic effects. For that reason, it has been studied in human NSCLC xenografts [35-37]. Olaparib is the first PARPi approved for the treatment of refractory ovarian cancer harboring $B R C A 1$ or $B R C A 2$ mutations. We have previously shown that treatment with $\mathrm{KJ}-28 \mathrm{~d}$ induced more frequent apoptotic cell death in $B R C A$ mutated ovarian cancer cells than olaparib did. It was noteworthy in this study that the combination of KJ-28d and IR also induced significantly more apoptotic cell deaths in NSCLC cells compared to combination treatment with olaparib and IR. Since we initially identified $\mathrm{KJ}-28 \mathrm{~d}$ as a PARPi, further studies need to be conducted to elucidate other modes of action, as they may be cytotoxic. Platinum-based agents are widely used for a broad range of solid tumors, including NSCLC, and are the most commonly studied combination partners of PARPi [26,31,38]. Likewise, our results demonstrated that KJ-28d significantly enhanced the sensitivity of A549 and H1299 cells to carboplatin or cisplatin. In addition, we observed synergistic cell growth inhibitions of both cell populations when treated with a combination of $\mathrm{KJ}-28 \mathrm{~d}$ with either paclitaxel or doxorubicin that constitute strong DNA-damaging therapeutic agents.

Besides the demonstrated inhibitory PARP activity of $\mathrm{KJ}-28 \mathrm{~d}$, the mechanisms responsible for $\mathrm{KJ}$-28d-induced cytotoxicity in wild-type BRCA cancer cells have not been fully uncovered in this study. We suggest that KJ-28d might be involved in the antitumor activity exhibited in NSCLC cells with wild-type $B R C A$ based on the experimentally exhibited markedly induced DNA DSBs and ROS generation at the latest examined time point $(24 \mathrm{~h})$. Structurally, KJ-28d contains the hydroxamic acid moiety found in histone deacetylase inhibitors (HDACi), including suberoylanilide hydroxamic acid. The hydroxamic acid moiety of HDACi acts as a chelator for zinc ions in the active site of histone deacetylases. To elucidate the possibility of HDAC inhibition, we examined the inhibitory activities of 1-11 HDAC isoforms using in vitro enzyme assays but observed little inhibitory activities of HDACs at $\mathrm{KJ}-28 \mathrm{~d}$ concentrations under $5 \mu \mathrm{M}$, as shown in Supplementary Table S2. Further structure-activity relationship studies are required to understand the inhibitory activities of PARP-1/2 as a PARPi and to investigate the mechanisms associated with KJ-28d-induced growth inhibition and apoptotic cell death in NSCLC cells.

In summary, KJ-28d was cytotoxic to BRCA-proficient cancer cells, including NSCLC cells. Treatment with $\mathrm{KJ}-28 \mathrm{~d}$ before IR led to increased DNA damage responses compared to treatment with KJ-28d or IR alone, resulting in the induction of apoptotic cell death. The combination of KJ-28d with carboplatin, cisplatin, paclitaxel, or doxorubicin considerably inhibited cell proliferation. In this 
context, KJ-28d might act as an effective anti-cancer therapeutic agent against both $B R C A$-deficient and -proficient cancer cells and might have further potential as an adjuvant when used in combination with radiotherapy or DNA-damaging agents. However, further investigations into the mechanisms of action of KJ-28d in cancer cells are warranted.

\section{Materials and Methods}

\subsection{Cell Culture}

Human lung cancer cells (A549, H1299, H460, and H1650) were obtained from American Type Culture Collection (ATCC, Manassas, VA, USA). Cells were maintained in Roswell Park Memorial Institute (RPMI) 1640 medium (Welgene, Gyeongsangbuk-do, Korea) supplemented with $10 \%$ fetal bovine serum (Welgene) and 100 units/mL penicillin-streptomycin solution (Gibco, Grand Island, NY, USA) at $37^{\circ} \mathrm{C}$ in a humidified $5 \% \mathrm{CO}_{2}$ atmosphere.

\subsection{Reagents}

The PARPi olaparib (AZD2281) was purchased from Selleckchem (Houston, TX, USA). Doxorubicin was purchased from Sigma-Aldrich (St. Louis, MO, USA). All reagents, including carboplatin (Dong-A ST, Seoul, Korea), cisplatin (JW Pharmaceutical, Seoul, Korea), and paclitaxel (Samyang Biopharm, Gyeonggi-do, Korea) were dissolved in dimethyl sulfoxide (DMSO; Sigma-Aldrich). MTT was purchased from Amresco (Solon, OH, USA). Primary antibodies used in this study included the following; anti-cleaved caspase 3 (D175, \#9661; Cell Signaling Technology; Danvers, MA, USA), phospho-histone H2AX (Ser 139, sc-517348), and glyceraldehyde 3-phosphate dehydrogenase (GAPDH, sc-47724; Santa Cruz Biotechnology; Dallas, TX, USA), and anti- $\beta$-actin (A5441; Sigma-Aldrich) antibodies.

\subsection{Cell Viability Assay}

Cell viability was assessed using the MTT colorimetric assay. Cells $\left(6 \sim 8 \times 10^{2}\right.$ cells/well $)$ were seeded into 96-well plates and treated with various concentrations of KJ-28d or a combination of anti-cancer drugs or IR. After 5 days of treatment, $10 \mu \mathrm{L}$ MTT $(0.5 \mathrm{mg} / \mathrm{mL})$ was added, and cells were further incubated for $3 \mathrm{~h}$. After removal of the supernatant, the resultant pellet was dissolved in DMSO. The absorbance of the resultant formazan was measured at $540 \mathrm{~nm}$ using a Multiskan EX plate reader (Thermo LabSystems, Waltham, MA, USA).

\subsection{Tumor Xenograft Mouse Models}

A549 and H1299 human lung cancer cell xenografts were established by s.c. implantation of $2 \times 10^{6}$ cultured cells into the thigh of the right hind leg of six-week-old mice. When tumor volumes had reached approximately $100 \mathrm{~mm}^{3}, \mathrm{KJ}-28 \mathrm{~d}(10 \mathrm{mg} / \mathrm{kg})$ was administered i.p. once per 2 or 3 days for seven times in total. All animal experiments were reviewed and approved by the Institutional Animal Care and Use Committee of Korea Institute of Radiological and Medical Sciences (kirams2018-0063, 2018).

\subsection{Detection of Intracellular ROS}

Either DMSO- or KJ-28d-treated cells $\left(5 \times 10^{5}\right)$ were further treated with $10 \mu \mathrm{M} \mathrm{CM}-\mathrm{H}_{2}$ DCFH-DA (Thermo Fisher Scientific, Rockford, IL, USA) for $30 \mathrm{~min}$ and then washed with phosphate-buffered saline (PBS). After trypsinization, cells were collected, washed, and resuspended in PBS. Inhibition of ROS was evaluated by treating cells with $5 \mathrm{mM}$ NAC $2 \mathrm{~h}$ prior to KJ-28d treatment. Intracellular ROS levels were detected using a CyFlow cube 6 flow cytometer (Sysmex Partec, Gorlitz, Germany) at excitation/emission wavelengths of $488 / 525 \mathrm{~nm}$. 


\subsection{Immunoblot Analysis}

A549 and H1299 cells $\left(1 \times 10^{6}\right)$ were seeded onto a $60 \mathrm{~mm}$ dish. Cell lysates were prepared by extracting proteins with radioimmunoprecipitation assay (RIPA) lysis buffer (Millipore, Billerica, MA, USA) supplemented with a protease inhibitor cocktail (Thermo Fisher Scientific). Equal amounts of proteins were separated using SDS-PAGE on $8 \%-13 \%$ gels and transferred to nitrocellulose membranes (Bio-Rad, Hercules, CA, USA). Membranes were blocked with 5\% skim milk in Tris-buffered saline-Tween 20 (TBST; $150 \mathrm{mM} \mathrm{NaCl}, 10 \mathrm{mM}$ Tris, $0.2 \%$ Tween 20; Sigma-Aldrich), followed by overnight incubation with primary antibodies at $4{ }^{\circ} \mathrm{C}$. Blots were developed using peroxidase-conjugated secondary antibody, and immunoreactive proteins were visualized using enhanced chemiluminescence reagents, according to the manufacturer's recommendations (Amersham, GE Healthcare, Buckinghamshire, UK). Protein bands were visualized using an ImageQuant LAS 4000 mini digital imaging system (GE Healthcare). Protein levels were analyzed using Image J software (National Institutes of Health, Bethesda, MD, USA). Experiments were repeated at least three times.

\subsection{Clonogenic Assay}

Cells were seeded on $60 \mathrm{~mm}$ culture dishes at various densities and then treated with DMSO or $\mathrm{KJ}-28 \mathrm{~d}(0.75 \mu \mathrm{M})$. After $2 \mathrm{~h}$, cells were treated with the indicated doses of $137 \mathrm{Cs} \gamma$-radiation. After $10 \mathrm{~d}$, colonies were fixed and stained with $1.5 \%$ methylene blue (Sigma-Aldrich) in methanol solution. Colonies containing $>50$ cells were counted. DER was calculated as the dose (Gy) of radiation that yielded a surviving fraction of 0.1 for DMSO-treated cells divided by that dose for KJ-28d-treated cells. The experiment was performed in triplicate.

\subsection{Annexin V/PI-Based Flow Cytometric Analysis}

Annexin $\mathrm{V}$ assays were performed according to the manufacturer's protocol (BD Pharmingen, San Diego, CA, USA). Briefly, 10,000 cells were plated into $60 \mathrm{~mm}$ plates and treated with KJ-28d $(10 \mu \mathrm{M})$ for $48 \mathrm{~h}$. Cells were harvested and incubated with $4 \mu \mathrm{L}$ allophycocyanin (APC)-conjugated annexin $\mathrm{V}(20 \mu \mathrm{g} / \mathrm{mL})$ and $4 \mu \mathrm{L}$ PI $(50 \mu \mathrm{g} / \mathrm{mL})$ for $15 \mathrm{~min}$. Fluorescence analyses were performed using flow cytometry (CyFlow cube 6). Cells were classified as early apoptotic (annexin V-positive/PI-negative), late apoptotic/necrotic (annexin V-positive/PI-positive), necrotic/dead (annexin V-negative/PI-positive), and live (annexin V-negative/PI-negative). Flow cytometry data were analyzed using FlowJo software (TreeStar Inc., Ashland, OR, USA).

\subsection{Combination Index}

CI scores were calculated using the CompuSyn software by Chou (CompuSyn Inc., Paramus, NJ, USA) [27] based on cell viability after treatment with single and paired drug concentrations. The CI equation for two drugs used is given below:

$$
\mathrm{CI}=\frac{(\mathrm{D}) \mathrm{A}}{(\mathrm{Dx}) \mathrm{A}}+\frac{(\mathrm{D}) \mathrm{B}}{(\mathrm{Dx}) \mathrm{B}}
$$

where (Dx)A is the concentration of drug A alone that inhibits $\mathrm{x} \%$, $(\mathrm{Dx}) \mathrm{B}$ is the concentration of drug $\mathrm{B}$ alone that inhibits $\mathrm{x} \%$, (D)A or (D)B is the portion of drug A or drug B in the combination (D)A + (D)B that inhibits $\mathrm{x} \%$. Thus, (D)A + (D)B also inhibits $\mathrm{x} \%$.

\subsection{Statistical Analyses}

Results are shown as means \pm SD. Data were analyzed using the two-tailed Student's $t$-test. Analysis of variance (ANOVA) and Tukey's post hoc test were used for 2 or 3 group comparisons. Differences between groups with $p$ values $<0.05$ were considered statistically significant. 
Supplementary Materials: Supplementary materials can be found at http://www.mdpi.com/1422-0067/20/23/ 6026/s1.

Author Contributions: Conceptualization: J.A., H.-K.C., and J.-S.K.; funding acquisition: J.A.; investigation: H.R., H.J.K., and T.H.N.B.; resources: S.-G.H. and J.K.; writing-original draft: J.A. and H.R.; writing-review and editing: J.-Y.S. and H.-K.C.

Funding: This research was supported by the Basic Science Research Program through the National Research Foundation of Korea (NRF) funded by the Ministry of Education (NRF-2016R1D1A1B03936420; NRF-2016R1D1A3B03935674), and the Korea Institute of Radiological and Medical Sciences funded by the Ministry of Science and ICT, Republic of Korea (50531-2019; 50538-2019).

Conflicts of Interest: The authors declare that they have no conflicts of interest.

\begin{tabular}{ll}
\multicolumn{2}{l}{ Abbreviations } \\
PARP-1 & Poly (ADP-ribose) polymerase-1 \\
PARPi & PARP inhibitor(s) \\
PARylation & Poly ADP-ribosylation \\
NSCLC & non-small cell lung cancer \\
DSB & double-strand breaks \\
IR & ionizing radiation \\
ROS & reactive oxygen species \\
CI & combination index
\end{tabular}

\section{References}

1. American-Cancer-Society. Cancer Facts \& Figures 2019; American Cancer Society: Atlanta, GA, USA, 2019.

2. Korea, N.C.C. Annual Report of Cancer Statistics in Korea in 2016; Ntational Cancer Center Korea: Gyeonggi-do, Korea, 2016. Available online: https://www.cancer.go.kr/lay1/bbs/S1T674C680/B/26/list.do (accessed on 29 November 2019).

3. Liu, C.Y.; Wang, C.L.; Li, S.H.; Hsu, P.C.; Chen, C.H.; Lin, T.Y.; Kuo, C.H.; Fang, Y.F.; Ko, H.W.; Yu, C.T.; et al. The efficacy of $40 \mathrm{mg}$ versus dose de-escalation to less than $40 \mathrm{mg}$ of afatinib (Giotrif) as the first-line therapy for patients with primary lung adenocarcinoma harboring favorable epidermal growth factor mutations. Oncotarget 2017, 8, 97602-97612. [CrossRef]

4. Jinesh, G.G.; Sambandam, V.; Vijayaraghavan, S.; Balaji, K.; Mukherjee, S. Molecular genetics and cellular events of K-Ras-driven tumorigenesis. Oncogene 2018, 37, 839-846. [CrossRef]

5. Chen, Y.; Chen, G.; Li, J.; Huang, Y.Y.; Li, Y.; Lin, J.; Chen, L.Z.; Lu, J.P.; Wang, Y.Q.; Wang, C.X.; et al. Association of Tumor Protein p53 and Ataxia-Telangiectasia Mutated Comutation With Response to Immune Checkpoint Inhibitors and Mortality in Patients With Non-Small Cell Lung Cancer. JAMA Netw. Open 2019, 2, e1911895. [CrossRef] [PubMed]

6. Fan, Y.; Zhu, X.; Xu, Y.; Lu, X.; Xu, Y.; Wang, M.; Xu, H.; Ding, J.; Ye, X.; Fang, L.; et al. Cell-Cycle and DNA-Damage Response Pathway Is Involved in Leptomeningeal Metastasis of Non-Small Cell Lung Cancer. Clin. Cancer Res. 2018, 24, 209-216. [CrossRef] [PubMed]

7. Alidousty, C.; Baar, T.; Martelotto, L.G.; Heydt, C.; Wagener, S.; Fassunke, J.; Duerbaum, N.; Scheel, A.H.; Frank, S.; Holz, B.; et al. Genetic instability and recurrent MYC amplification in ALK-translocated NSCLC: A central role of TP53 mutations. J. Pathol. 2018, 246, 67-76. [CrossRef] [PubMed]

8. Postel-Vinay, S.; Vanhecke, E.; Olaussen, K.A.; Lord, C.J.; Ashworth, A.; Soria, J.C. The potential of exploiting DNA-repair defects for optimizing lung cancer treatment. Nat. Rev. Clin. Oncol. 2012, 9, 144-155. [CrossRef] [PubMed]

9. Wang, Y.S.; Chen, J.; Cui, F.; Wang, H.; Wang, S.; Hang, W.; Zeng, Q.; Quan, C.S.; Zhai, Y.X.; Wang, J.W.; et al. LKB1 is a DNA damage response protein that regulates cellular sensitivity to PARP inhibitors. Oncotarget 2016, 7, 73389-73401. [CrossRef] [PubMed]

10. Singh, A.; Misra, V.; Thimmulappa, R.K.; Lee, H.; Ames, S.; Hoque, M.O.; Herman, J.G.; Baylin, S.B.; Sidransky, D.; Gabrielson, E.; et al. Dysfunctional KEAP1-NRF2 interaction in non-small-cell lung cancer. PLoS Med. 2006, 3, e420. [CrossRef] [PubMed]

11. Rojo de la Vega, M.; Chapman, E.; Zhang, D.D. NRF2 and the Hallmarks of Cancer. Cancer Cell 2018, 34, 21-43. [CrossRef] 
12. Virag, L.; Szabo, C. The therapeutic potential of poly(ADP-ribose) polymerase inhibitors. Pharmacol. Rev. 2002, 54, 375-429. [CrossRef]

13. Dantzer, F.; Ame, J.C.; Schreiber, V.; Nakamura, J.; Menissier-de Murcia, J.; de Murcia, G. Poly(ADP-ribose) polymerase-1 activation during DNA damage and repair. Methods Enzymol. 2006, 409, 493-510. [PubMed]

14. Kalimutho, M.; Bain, A.L.; Mukherjee, B.; Nag, P.; Nanayakkara, D.M.; Harten, S.K.; Harris, J.L.; Subramanian, G.N.; Sinha, D.; Shirasawa, S.; et al. Enhanced dependency of KRAS-mutant colorectal cancer cells on RAD51-dependent homologous recombination repair identified from genetic interactions in Saccharomyces cerevisiae. Mol. Oncol. 2017, 11, 470-490. [CrossRef] [PubMed]

15. Kawahara, N.; Ogawa, K.; Nagayasu, M.; Kimura, M.; Sasaki, Y.; Kobayashi, H. Candidate synthetic lethality partners to PARP inhibitors in the treatment of ovarian clear cell cancer. Biomed. Rep. 2017, 7, 391-399. [CrossRef] [PubMed]

16. Sizemore, S.T.; Mohammad, R.; Sizemore, G.M.; Nowsheen, S.; Yu, H.; Ostrowski, M.C.; Chakravarti, A.; Xia, F. Synthetic Lethality of PARP Inhibition and Ionizing Radiation is p53-dependent. Biomed. Rep. 2017, 7, 391-399. [CrossRef] [PubMed]

17. Alli, E.; Sharma, V.B.; Sunderesakumar, P.; Ford, J.M. Defective repair of oxidative dna damage in triple-negative breast cancer confers sensitivity to inhibition of poly(ADP-ribose) polymerase. Cancer Res. 2009, 69, 3589-3596. [CrossRef] [PubMed]

18. Hastak, K.; Alli, E.; Ford, J.M. Synergistic chemosensitivity of triple-negative breast cancer cell lines to poly(ADP-Ribose) polymerase inhibition, gemcitabine, and cisplatin. Cancer Res. 2010, 70, 7970-7980. [CrossRef] [PubMed]

19. Turner, N.; Tutt, A.; Ashworth, A. Hallmarks of 'BRCAness' in sporadic cancers. Nat. Rev. Cancer 2004, 4, 814-819. [CrossRef]

20. Liu, Q.; Gheorghiu, L.; Drumm, M.; Clayman, R.; Eidelman, A.; Wszolek, M.F.; Olumi, A.; Feldman, A.; Wang, M.; Marcar, L.; et al. PARP-1 inhibition with or without ionizing radiation confers reactive oxygen species-mediated cytotoxicity preferentially to cancer cells with mutant TP53. Oncogene 2018, 37, $2793-2805$. [CrossRef]

21. Ryu, H.; Ahn, J.; Choi, H.K. Novel Benzamide Derivatives: Synthesis and Bioactivity as Potent PARP-1 Inhibitors. Bull. Korean Chem. Soc. 2017, 38, 935-943. [CrossRef]

22. Nile, D.L.; Rae, C.; Hyndman, I.J.; Gaze, M.N.; Mairs, R.J. An evaluation in vitro of PARP-1 inhibitors, rucaparib and olaparib, as radiosensitisers for the treatment of neuroblastoma. BMC Cancer 2016, 16, 621. [CrossRef]

23. Gill, S.J.; Travers, J.; Pshenichnaya, I.; Kogera, F.A.; Barthorpe, S.; Mironenko, T.; Richardson, L.; Benes, C.H.; Stratton, M.R.; McDermott, U.; et al. Combinations of PARP Inhibitors with Temozolomide Drive PARP1 Trapping and Apoptosis in Ewing's Sarcoma. PLoS ONE 2015, 10, e0140988. [CrossRef] [PubMed]

24. Donawho, C.K.; Luo, Y.; Luo, Y.; Penning, T.D.; Bauch, J.L.; Bouska, J.J.; Bontcheva-Diaz, V.D.; Cox, B.F.; DeWeese, T.L.; Dillehay, L.E.; et al. ABT-888, an orally active poly(ADP-ribose) polymerase inhibitor that potentiates DNA-damaging agents in preclinical tumor models. Clin. Cancer Res. 2007, 13, 2728-2737. [CrossRef]

25. Palma, J.P.; Wang, Y.C.; Rodriguez, L.E.; Montgomery, D.; Ellis, P.A.; Bukofzer, G.; Niquette, A.; Liu, X.; Shi, Y.; Lasko, L.; et al. ABT-888 confers broad in vivo activity in combination with temozolomide in diverse tumors. Clin. Cancer Res. 2009, 15, 7277-7290. [CrossRef] [PubMed]

26. Ramalingam, S.S.; Blais, N.; Mazieres, J.; Reck, M.; Jones, C.M.; Juhasz, E.; Urban, L.; Orlov, S.; Barlesi, F.; Kio, E.; et al. Randomized, Placebo-Controlled, Phase II Study of Veliparib in Combination with Carboplatin and Paclitaxel for Advanced/Metastatic Non-Small Cell Lung Cancer. Clin. Cancer Res. 2017, 23, 1937-1944. [CrossRef] [PubMed]

27. Chou, T.C. Drug combination studies and their synergy quantification using the Chou-Talalay method. Cancer Res. 2010, 70, 440-446. [CrossRef] [PubMed]

28. Kastenhuber, E.R.; Lowe, S.W. Putting p53 in Context. Cell 2017, 170, 1062-1078. [CrossRef] [PubMed]

29. Yin, Z.X.; Hang, W.; Liu, G.; Wang, Y.S.; Shen, X.F.; Sun, Q.H.; Li, D.D.; Jian, Y.P.; Zhang, Y.H.; Quan, C.S.; et al. PARP-1 inhibitors sensitize HNSCC cells to APR-246 by inactivation of thioredoxin reductase 1 (TrxR1) and promotion of ROS accumulation. Oncotarget 2018, 9, 1885-1897. [CrossRef] [PubMed] 
30. Reck, M.; Blais, N.; Juhasz, E.; Gorbunova, V.; Jones, C.M.; Urban, L.; Orlov, S.; Barlesi, F.; Kio, E.; Keilholz, U.; et al. Smoking History Predicts Sensitivity to PARP Inhibitor Veliparib in Patients with Advanced Non-Small Cell Lung Cancer. J. Thorac. Oncol. 2017, 12, 1098-1108. [CrossRef] [PubMed]

31. Mizugaki, H.; Yamamoto, N.; Nokihara, H.; Fujiwara, Y.; Horinouchi, H.; Kanda, S.; Kitazono, S.; Yagishita, S.; Xiong, H.; Qian, J.; et al. A phase 1 study evaluating the pharmacokinetics and preliminary efficacy of veliparib (ABT-888) in combination with carboplatin/paclitaxel in Japanese subjects with non-small cell lung cancer (NSCLC). Cancer Chemother. Pharmacol. 2015, 76, 1063-1072. [CrossRef] [PubMed]

32. Tuli, R.; Surmak, A.J.; Reyes, J.; Armour, M.; Hacker-Prietz, A.; Wong, J.; DeWeese, T.L.; Herman, J.M. Radiosensitization of Pancreatic Cancer Cells In Vitro and In Vivo through Poly (ADP-ribose) Polymerase Inhibition with ABT-888. Transl. Oncol. 2014, 7, 439-445. [CrossRef]

33. Tuli, R.; Shiao, S.L.; Nissen, N.; Tighiouart, M.; Kim, S.; Osipov, A.; Bryant, M.; Ristow, L.; Placencio-Hickok, V.; Hoffman, D.; et al. A phase 1 study of veliparib, a PARP-1/2 inhibitor, with gemcitabine and radiotherapy in locally advanced pancreatic cancer. EBioMedicine 2019, 40, 375-381. [CrossRef]

34. Tyldesley, S.; Boyd, C.; Schulze, K.; Walker, H.; Mackillop, W.J. Estimating the need for radiotherapy for lung cancer: An evidence-based, epidemiologic approach. Int. J. Radiat. Oncol. Biol. Phys. 2001, 49, 973-985. [CrossRef]

35. Wang, L.; Mason, K.A.; Ang, K.K.; Buchholz, T.; Valdecanas, D.; Mathur, A.; Buser-Doepner, C.; Toniatti, C.; Milas, L. MK-4827, a PARP-1/-2 inhibitor, strongly enhances response of human lung and breast cancer xenografts to radiation. Invest. New Drugs 2012, 30, 2113-2120. [CrossRef]

36. Senra, J.M.; Telfer, B.A.; Cherry, K.E.; McCrudden, C.M.; Hirst, D.G.; O'Connor, M.J.; Wedge, S.R.; Stratford, I.J. Inhibition of PARP-1 by olaparib (AZD2281) increases the radiosensitivity of a lung tumor xenograft. Mol. Cancer Ther. 2011, 10, 1949-1958. [CrossRef]

37. Albert, J.M.; Cao, C.; Kim, K.W.; Willey, C.D.; Geng, L.; Xiao, D.; Wang, H.; Sandler, A.; Johnson, D.H.; Colevas, A.D.; et al. Inhibition of poly(ADP-ribose) polymerase enhances cell death and improves tumor growth delay in irradiated lung cancer models. Clin. Cancer Res. 2007, 13, 3033-3042. [CrossRef]

38. Hu, X.L.; Feng, J.H.; Pham, T.A.; Ma, H.Y.; Ma, M.X.; Song, R.; Shen, W.; Xiong, F.; Zhang, X.Q.; Ye, W.C.; et al. Identification of amentoflavone as a potent highly selective PARP-1 inhibitor and its potentiation on carboplatin in human non-small cell lung cancer. Phytomedicine 2018, 50, 88-98. [CrossRef] 